Vietnam Academy of Science and Technology
Vietnam Journal of Earth Sciences
http://www.vjs.ac.vn/index.php/jse

\title{
Inverse analysis for transmissivity and the Red river bed's leakage factor for Pleistocene aquifer in Sen Chieu, Hanoi by pumping test under the river water level fluctuation
}

\author{
Trieu Duc Huy, ${ }^{1}$ Tong Ngoc Thanh ${ }^{1}$, Nguyen Van Lam², Nguyen Van Hoang*3 \\ ${ }^{1}$ Vietnam National Center for Water Resources Planning and Investigation \\ ${ }^{2}$ Hanoi University of Geology and Mining \\ ${ }^{3}$ Institute of Geological Sciences, Vietnam Academy of Science and Technology
}

Received 20 April 2017; Received in revised form 26 October 2017; Accepted 15 November 2017

\begin{abstract}
Aquifer parameters and riverbed hydraulic resistance to an aquifer have an important role in the quantitative assessment of groundwater sources, especially the aquifer recharge from river. The analytical determination of aquifer parameters and riverbed hydraulic resistance to the aquifer is rather complicated in case if the water level in the river fluctuates before and during the pumping test time. This is especially true for Pleistocene aquifer along the Red River in Hanoi city, where the riverbed has been changed very much during the recent decades. A trial-error inverse analysis in the parameters' determination by a group pumping test data obtained with a test located close to the Red river bank in Sen Chieu area, Phuc Tho district, Hanoi city was carried out. Before and during the pumping test time the water level in the river changed five times. The results have shown that the Pleistocene aquifer has a relatively high hydraulic conductivity of $55.5 \mathrm{~m} /$ day, which provides a good role in the transport of a large volume of water recharged by the river to the abstraction wells located near the river. The aquifer storage coefficient had lightly decreased with the pumping time, which is corresponding to the physical nature of that the aquifer stativity is a function of the aquifer pressure. A special point is worthwhile to be noted that the Red river bed resistance to the Pleistocene is very low, about 0.537 days, which is corresponding to the increase of the distance from the river bank further from the well in $28.4 \mathrm{~m}$ to have the river as a specified water level boundary of the aquifer. In contrast, the 1990's investigations had found that the Red river bed resistance to the Pleistocene aquifer to be about 130 days (Tran Minh, 1984), which is corresponding to the increase of the distance from the river bank further from the well in a thousand of meters to have the river as a specified water level boundary for the aquifer.
\end{abstract}

Keywords: Group-well pumping test; pleistocene aquifer; riverbed resistance; leakage factor.

C)2018 Vietnam Academy of Science and Technology

\section{Introduction}

The interaction between surface water and groundwater has a great attention of water

"Corresponding author, Email: N_V_Hoang_VDC@yahoo.com resources workers, both managers and researchers thanks to its important role in both long-term studies for determining the effects of hydrologic and climatic conditions on the groundwater resources and in short-term tests 
to determine local-scale effects of pumping on the exchange of surface water bodies and groundwater aquifers (John H. Cushman and Daniel M. Tartakovsky, 2017). That challenging problem attracted many researchers to deep into the study, although still leaving an open door for new researches in that direction.

Christensen (2000) studied experimental and hydrogeological conditions which drawdown analysis can be expected to produce aquifer parameters and leakage factor, and then proposed some recommendations for the design of pumping test near a stream in order to achieve the determination of the parameters, especially a methodology used to estimate the duration of the pumping test in which the desired accuracy of either the parameters or the stream flow predicted from these estimates. Hunt et al. (2001) had carried a field experiment to measure drawdowns in observation wells and stream depletion flows that occurred when water was abstracted from a well beside a stream. The analysis used early time drawdowns with a match point method to determine aquifer transmissivity and storage coefficient, and stream depletion measurements at later times used to determine leakage factor. Sophocleous (2001) had presented that a great requirement for an advanced conceptual and another modeling of groundwater and surface water systems, for a broader perspective of such interactions across and between surface water bodies, interface hydraulic characterization and spatial variability.

Fox (2004) had carried out a pumping test next to the backwater stream channel at the Tamarack State Wildlife Area in eastern Colorado, analyzed the drawdown measured in observation wells and predicted drawdown by analytical solutions to derive simultaneously estimates of aquifer parameters and streambed resistance to the aquifer. The author had come to the conclusion that the analytical solutions are capable of estimating reasonable values of both aquifer and streambed parameters. However, the changes in the water level in the stream during the test time and a varying water level profile at the beginning of the pumping test influence the application of the analytical solutions.

Lough and Hunt (2006) had carried out a complicated group-well pumping test besides a stream to estimate aquifer and streambed resistance parameters and a sensitivity analysis to determine the relative importance of each parameter in the stream depletion calculations.

Therefore, the analysis of aquifer parameters based on the field pumping test data is a rather complicated work for the cases of a multiple or single aquifer (with leakage) with a boundary of a specified fluctuating water level, or head-dependent boundary with fluctuating water levels at the boundary, or boundary of a varying inflow. For aquifers with headdependent boundary (leakage) boundary, the accurate determination of leakage factor would provide an accurate assessment of the recharge from the river to the aquifer, which is very important for both sustainable groundwater and river water management.

The Red river plays an important role in recharging the Pleistocene aquifer since the aquifer groundwater level had been decreased to a level lower than the river's water level. This is especially true for the present conditions when an extensive sand and gravel excavation in the river (Vu Tat Uyen and Le Manh Hung, 2013; Pham Dinh, 2016) has remarkably changed the hydraulic interaction between the river and the Pleistocene aquifer. Therefore, the determination of the most accurate leakage factor of the Red river to the Pleistocene aquifer has a valuable scientific and practical importance.

Within the implementation of the project "Groundwater of Urban are of Hanoi" (Trieu Duc Huy, 2015), several group-well pumping tests had been carried out for determination of 
aquifer parameters. Some the group-well pumping tests are located along the Red river for the purpose of determination of the riverbed's hydraulic resistance to the Pleistocene aquifer. Under the river water level fluctuations, the aquifer parameter determination is much more complicated than the case of a constant river water level.

The inverse analysis of the aquifer parameters including the leakage factor for the Pleistocene aquifer becomes more complicated due to the Red river water level fluctuation before and during the group-well pumping test.

\section{Background}

The main productive groundwater aquifer in Hanoi area is the Pleistocene aquifer. General hydrogeological conditions of the area may be referred to many publications, for example, Nguyen Minh Lan, 2014; Tong Ngoc Thanh et al., 2017; Nguyen The Chuyen et al., 2017. This work is dealing with a particular site in Sen Chieu commune, Phuc Tho district, Hanoi city where a group-well pumping test was carried. The testing wells in the direction perpendicular to the river bank is shown in Figure 1: central pumping well CHN1, observation well $\mathrm{CHN} 1-1 \mathrm{~B}$ and $\mathrm{CHN1-2B}$.

The Pleistocene aquifer consists of upper Pleistocene sub-aquifer (qp2) and of lower Pleistocene sub-aquifer (qp1). There is no aquitard between qp2 and qp1 in the testing site. Water level drawdown during the pumping and recovery after pumping stop were measured in all wells (Figure 1).

The following are the arguments for selection of the conceptual aquifer scheme used in the inverse analysis:

- The Pleistocene aquifer (with two subaquifer qp2 and qp1) is a confined aquifer with an impermeable layer on the top and in the bottom. The top of the aquifer can be considered as impermeable thanks to the presence of Vinh Phuc clay and silty clay layer of a thickness of about $10 \mathrm{~m}$. The uderneath Neogene formation consists of sandstone, gritstone, and siltstone with the thickness of $50 \mathrm{~m}$ to $350 \mathrm{~m}$ and transmissivity of $55 \mathrm{~m}^{2} /$ day to $840 \mathrm{~m}^{2} /$ day. The Neogene formation in the South-East of Hanoi from Nhat Tan, Xuan La has a better transmissivity (Nguyen Minh Lan, 2014). If the average thickness of Neogene in the testing site of about $100 \mathrm{~m}$ then the permeability is about $0.55 \mathrm{~m} /$ day. Therefore, the leakage from the Neogene formation into the Pleistocene aquifer during the pumping test would be negligible in the aquifer parameter inverse analysis.

- The Pleistocene aquifer has hydraulic connectivity with the Red river: Two possible boundary conditions of the Pleistocene aquifer can be used for the Red river: (1) The first kind of boundary condition (Dirichlet boundary: specified water level) by increasing the distance from the well to the river edge in a distance of $\Delta L$, which is a function of the aquifer parameters and the river's bed layer above the aquifer (this is described in paragraph 2); (2) Third kind of boundary condition (mixed boundary: water level dependence): the recharge from the river to the aquifer is a function of the river water level and aquifer water level and the river bottom leakage factor).

In this work, the first kind of boundary condition is used in the analysis. The Red river water level fluctuations in the river before and during the pumping test time had caused groundwater level changes in the group-well pumping test wells. Those groundwater level changes need to be taken into account in the parameter analysis.

Figure 2 showing a river water level fluctuations in the area of groundwater pumping test in an aquifer having hydraulic interaction with the river for used for illustrating their effect on the groundwater level fluctuations in the following formulation. 
Vietnam Journal of Earth Sciences, 40(1), 26-38

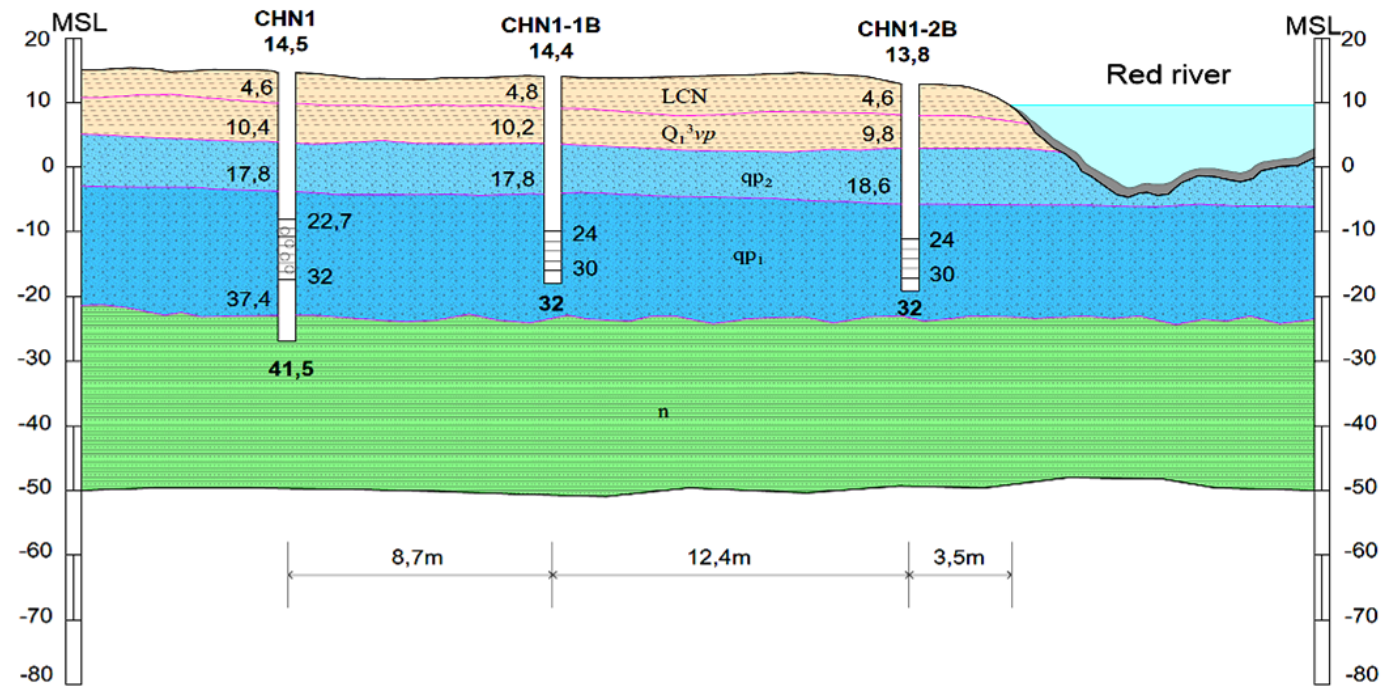

Figure 1. Cross section though the testing wells perpendicular to the Red river bank

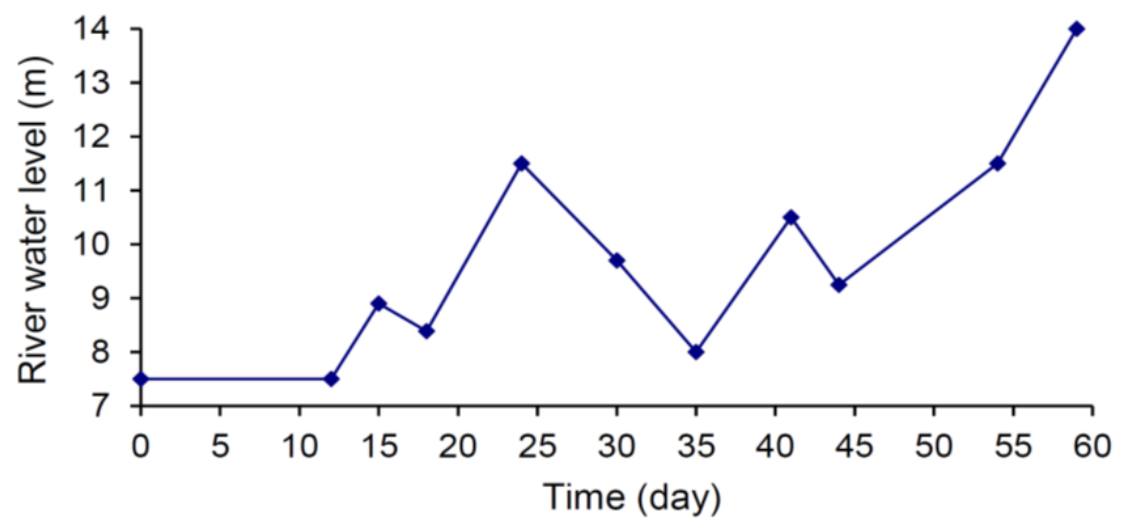

Figure 2. River water level fluctuations which cause the groundwater level fluctuations

The river water level changes illustrated in the Figure 2 can lead to the change $\Delta h$ of groundwater level at a distance $x$ in accordance with (Mironhenko V.A. and Shestakov V.M., 1974; Nguyen Quoc Thanh and Nguyen Van Hoang, 2007) by the following formula:

$$
\Delta h=V_{0} t R(\lambda)+\sum_{i=1}^{n}\left(V_{i}-V_{i-1}\right)\left(t-t_{i}\right) R\left(\lambda_{i}\right)
$$

In which $\Delta h$ - magnitude of groundwater level change (m) (up/down) from time $t=0$ to $t, V_{0}$ - river water level change speed (m/day) from time $t=0$ to $t_{1}, t$ - time counted from the moment the river water level started to change (day) to the time moment of calculation.

$$
R(\lambda)=\left(1+2 \lambda^{2}\right) \operatorname{erfc}(\lambda)-\frac{2}{\sqrt{\pi}} \lambda e^{-\lambda^{2}} ; \lambda=\frac{x+\Delta L}{2 \sqrt{a t}}
$$

In which: $\operatorname{erfc}()$ - complementary error function; $x$ - distance from the river edge to the considered point (m), $\Delta L$ - an increased distance equivalent to the riverbed resistance to the aquifer (m); $a=K m / S^{*}\left(\mathrm{~m}^{2} /\right.$ day); $K$ - hydraulic conductivity ( $\mathrm{m} /$ day); $m$-aquifer thickness $(\mathrm{m}) ; S^{*}$ - aquifer storage coefficient; $V_{i}$ - 
river water level change speed from time $t_{i-1}$ to $t_{i}(\mathrm{~m} /$ day) (with sign "+" if the river water level increases and with sign "-" if the river water level decreases).

The increased distance equivalent to the

$$
\Delta L=\sqrt{A_{0} K m} \times \operatorname{cth}\left(\frac{0.5 B^{0}}{\sqrt{A_{0} K m}}\right) ; \quad A_{0}=\frac{m_{0}}{K_{0}} ; \quad \operatorname{cth}(\alpha)=\frac{e^{\alpha}+e^{-\alpha}}{e^{\alpha}-e^{-\alpha}}
$$

In which: $B^{0}$ - the river width (distance between the two river edges) (m); $A_{0}$ - hydraulic resistance (day); $1 / A_{0}$ - leakage factor (1/day).

Groundwater flow analytical analyses require prototype aquifer distribution such as infinite or semi-infinite. For semi-infinite aquifer with the First kind of boundary condition a principle of super-imposition of flow with the introduction of so called imaginary wells is used to have an infinite aquifer distribution (Figure 3), where the river bed's resistanceequivalent length is implicitly in the $L$ value. river bed resistance to the aquifer $\Delta L$ is determined in order to apply the First kind boundary condition. $\Delta L$ is determined by the following formula (Mironhenko V.A. and Shestakov V.M., 1974):

- The groundwater level drawdown in the pumping well having $100 \%$ of well completeness is determined by the following formula (refer to Fetter, 2001; Nguyen Van Hoang, 2016):

$$
s_{L K}=\frac{0.366 Q}{T} \lg \frac{2 L}{r_{L K}}
$$

- The groundwater level drawdown in the pumping well:

$$
s_{Q S}=\frac{0.366 Q}{T} \lg \frac{\left(2 L-r_{Q S}\right)}{r_{Q S}}
$$

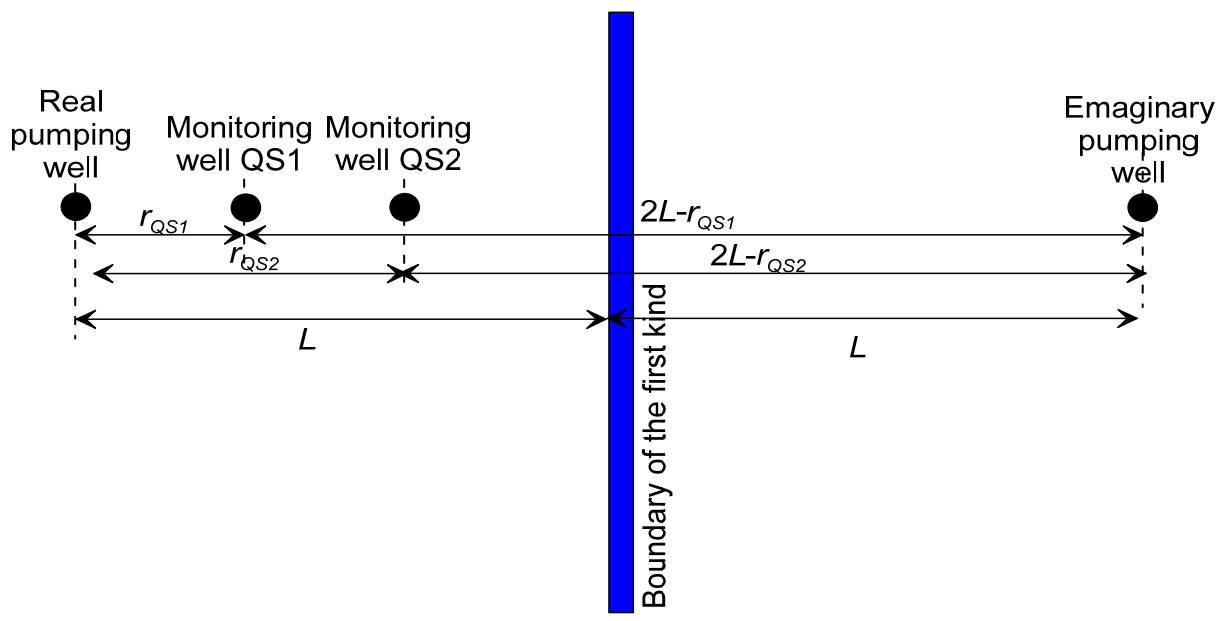

Figure 3. Analysis scheme for semi-infinite aquifer with boundary of the first kind

In which: $s$ is drawdown (m); $Q$ is pumping rate $\left(\mathrm{m}^{3} /\right.$ day); $T$ is aquifer transmissivity; $L K$ stands for pumping well; $Q S$ stands for observation well; $r_{l k}$ is pumping well's radius (m); $r_{Q S}$ is distance from pumping well to observation well (m); $L$ is distance from pumping well to the river edge plus equivalent river bed's resistance (m) (Figure 3).
For the case when there are two wells in a line which is perpendicular to the river edge and the water level in the specified head boundary is a constant, the aquifer transmissivity and the $L$ value are determined by a system of two equation (4) and (5). Therefore the river bed's resistance-equivalent length is equal to the calculated $L$ minus the field distance $L$. 
Since there are groundwater level changes thanks to the river water level fluctuations, in order to determine $T$ and $L$ it requires to introduce the value of groundwater change $\Delta(\Delta h)$ due to the river water level fluctuation. The value of $\Delta(\Delta h)$ is the groundwater level change $\Delta h$ at any time minus the groundwater level change $\Delta h_{0}$ at the moment just before pumping started. Putting $\Delta(\Delta h)=\Delta h-\Delta h_{0}$ into (4) and (5) for observation well $Q S 1$ and $Q S 1$ results in:

$$
\left\{\begin{array}{l}
s_{Q S 1}=\frac{0.366 Q_{H}}{T} \lg \frac{\left(2 L-r_{Q S 1}\right)}{r_{Q S 1}}+\Delta(\Delta h)_{Q S 2} \\
s_{Q S 2}=\frac{0.366 Q_{H}}{T} \lg \frac{\left(2 L-r_{Q S 2}\right)}{r_{Q S 2}}+\Delta(\Delta h)_{Q S 2}
\end{array}\right.
$$

\section{Data and Method}

\subsection{Data}

Within the implementation of the project "Groundwater of Urban are of Hanoi" (Trieu Duc Huy, 2015), one of several group-well pumping tests was carried out in Sen Chieu commune, Phuc Tho district, Hanoi city in a short distance from the Red river edge. The testing wells in the direction perpendicular to the river bank is shown in Figure 1: central pumping well CHN1 is $24.6 \mathrm{~m}$ from the river edge with a constant pumping rate of 9.37 $1 / \mathrm{s}=809.57 \mathrm{~m}^{3} /$ day, the pumping time was about 3000 minutes); observation well CHN11B (like QS1) is $8.7 \mathrm{~m}$ from the pumping well (15.9 $\mathrm{m}$ from the river edge) and observation well CHN1-2B (like QS1) is $21.1 \mathrm{~m}$ from the pumping well ( $3.5 \mathrm{~m}$ from the river edge).

The Pleistocene aquifer thickness is $27 \mathrm{~m}$, which consists of $7.4 \mathrm{~m}$ of Upper Pleistocene sub-aquifer (qp2) and $19.7 \mathrm{~m}$ of lower Pleistocene sub-aquifer (qp1). There is no aquitard between $\mathrm{qp} 2$ and $\mathrm{qp} 1$ in the testing site. The pumping from Pleistocene aquifer lasted from 15h50 the 10th of Dec. 2015 to $9 \mathrm{~h} 00$ the 12th of Dec. 2015. Water level drawdown during the pumping and recovery after pumping stop were measured in all wells.

The Red river water level was monitored and recorded at Son Tay hydrological station every 6 hours and is presented in Figure 4: for 60 hours before pumping started and for 70 hours after pumping started.

\subsection{Method}

The Red river water level fluctuations and four speeds of the river water level rising or declining have been determined and presented for the time expressed relatively to pumping start $(t=0)$ is presented in Figure 5.

By Eq. (1) with Eq. (2) and (3) and the Red river water level changes in Figure 4 the change of groundwater level at any borehole of the testing group CHN1 of wells can be determined upon given values of $T, S^{*}$ and $A_{0}$.

First of all, an initial assessment of groundwater water level change (increase or decrease) caused by the Red river water level fluctuations at the testing site. Among the parameters $T, S^{*}$ and $A_{0}$, parameter $A_{0}$ is the most concerned parameter in this work and is a most variable parameter since the hydraulic conductivity $K_{0}$ of the river bed's silty layer is in a large range from $0.001 \mathrm{~m} /$ day to 0.01 $\mathrm{m}$ /day (Fletcher, 1987), which correspondingly gives $A_{0}$ a value from 20 days to 200 days for the thickness of the river bed of $0.2 \mathrm{~m}$. For the extensive sand and gravel excavation in from the river $(\mathrm{Vu}$ Tat Uyen and Le Manh Hung, 2013; Pham Dinh, 2016), the river bed's silty layer may not be existing, $A_{0}$ would be a very small value, even close to zero. It is worthwhile to note that several decades ago in accordance to Tran Minh (1984), $A_{0}$ is about 130 days (mostly because the sand and gravel excavation was not too extensive as present).

The initial assessment of groundwater level change at the testing site caused by the Red river water level fluctuations, $T=1300$ $\mathrm{m}^{2} /$ day, $S^{*}=0.0001$ and $A_{0}=5$ days are used with the river water level data from the 60 days before pumping started. The initial pre- 
Trieu Duc Huy, et al./Vietnam Journal of Earth Sciences 40 (2018)

dicted groundwater level decrease or increase relatively to the groundwater level at the moment of 60 hours before pumping started is presented in Figure 6 for the central well CHN1. From that initial predicted groundwater level decrease or increase, predicted groundwater level change relatively to the groundwater level at the moment of pumping start can be determined and presented in Figure 7 for the central well CHN1, which is needed to be abstracted from the measured groundwater level in the central well CHN1 during the pumping test in parameter analysis. Similarly, the groundwater level change relatively to the groundwater level at the moment of pumping start need to be determined for other wells CHN1-1B and CHN1-2B.

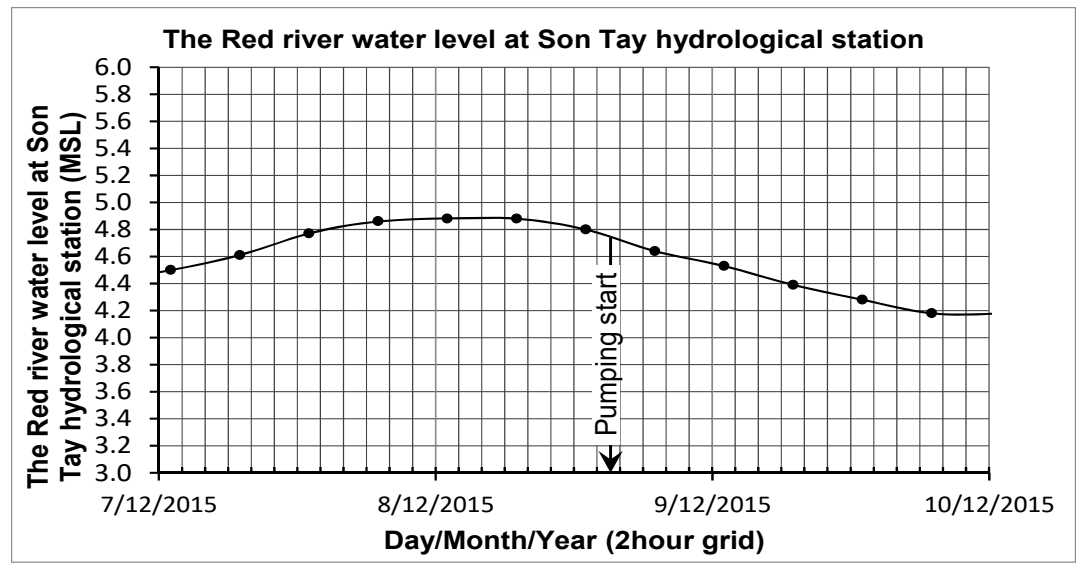

Figure 4. The Red river water level before and during the pumping test

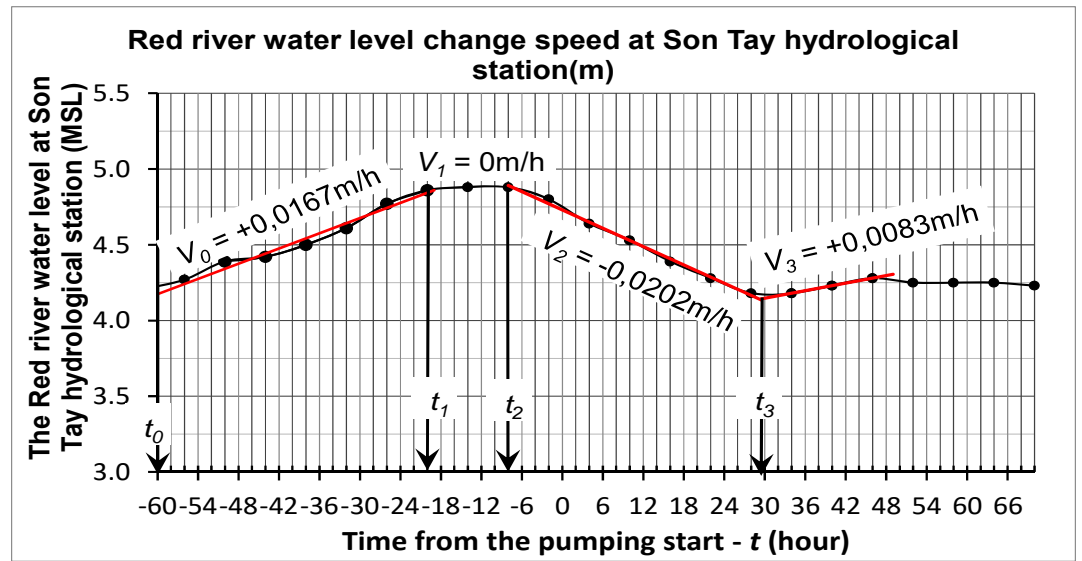

Figure 5. The Red river water level and its increase/decrease speed before and during the pumping test

3.1.1. Inverse analysis for aquifer parameters from group-well pumping test data CHNI

If a model structure is determined, the parameter identification based on the observed states and other available information is called inverse analysis (Ne-Zheng Sun, 1994). In a certain sense, parameter identification is an inverse of a forward problem. If the output of the forward problems (in this case, groundwater level) are the input and the aquifer parameters 
are the output then parameter identification are often called inverse problem (Ne-Zheng Sun,
1994), regardless, the model is numerical or analytical.

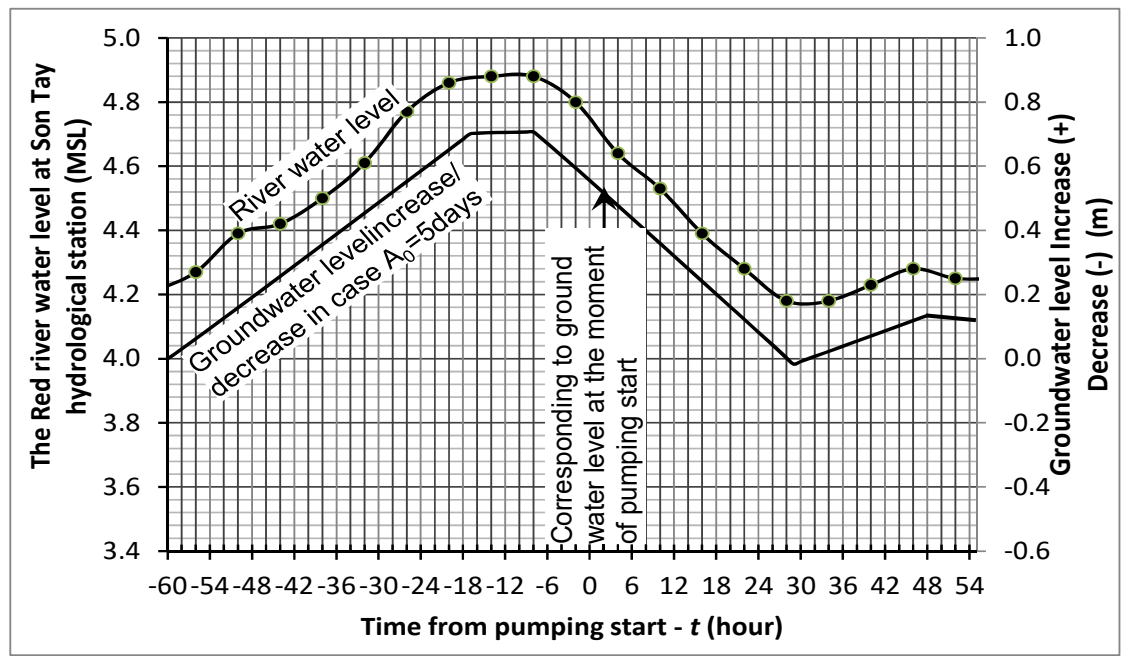

Figure 6. Initial predicted groundwater level decrease/increase at well CHN1 caused by the Red river water level fluctuations before and during pumping test

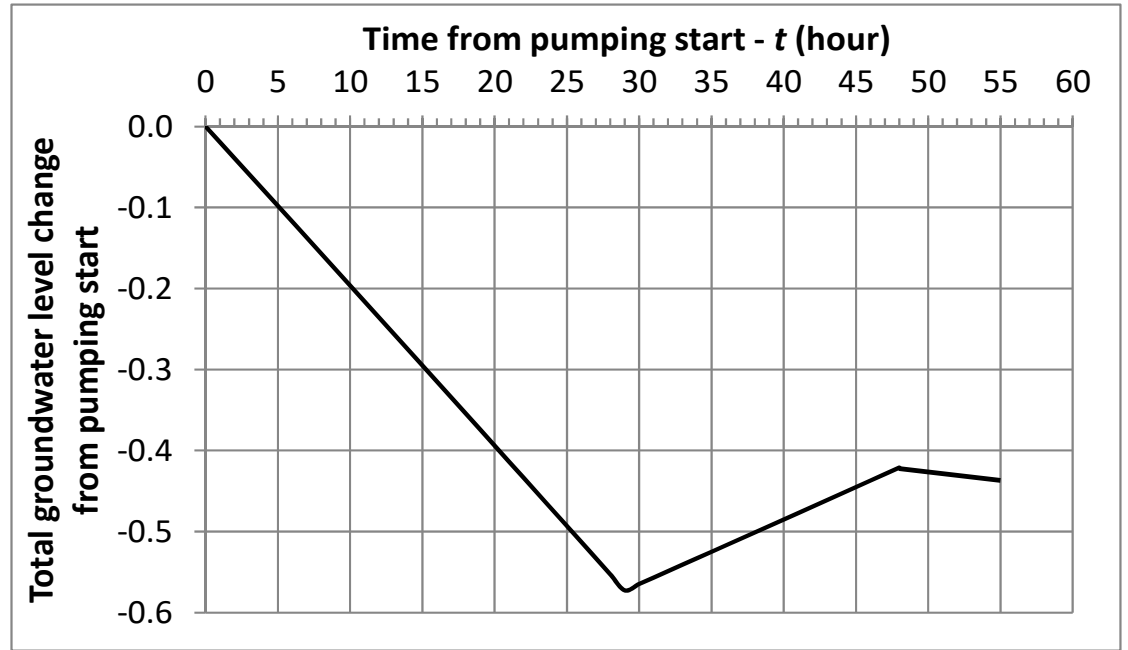

Figure 7. Initial predicted groundwater level change relatively to the groundwater level at the beginning of pumping at well $\mathrm{CHN}$

First, the aquifer storage coefficient $S^{*}$ determined by Cooper-Jacob method to determined aquifer storage coefficient with determination of so-called zero drawdowndistance (refer to Fletcher, 1987) as follows:

$$
\frac{2.25 T t}{S^{*} r_{0}^{2}}=1 \Rightarrow S^{*}=\frac{2.25 T t}{r_{0}^{2}}
$$

In which: $t$ is the time after pumping started (days) and $r_{0}$ is the distance (m) at which the drawdown is zero (the groundwater 
Trieu Duc Huy, et al./Vietnam Journal of Earth Sciences 40 (2018)

level just stars to decline) at that time $t$. The distance drawdown lines at different yearly pumping time area used for the purpose.

This obtained storage coefficient can be considered as "real value" since the method used is considered as the most reliable when time drawdown in observation wells are used. Therefore, the inverse analysis in this paragraph is using that storage coefficient value for determination of $T$ and $A_{0}$ and also $\Delta L$. The inverse analysis is using trial-anderror approach as follows.

3.1.2. Interpretation of the groundwater drawdown in the testing wells

The groundwater level drawdown in the testing wells are presented in Figure 8-10 have shown that the groundwater level in the wells started to be stabilized with small fluctuations at the 120 minutes of pumping in the pumping well $\mathrm{CHN} 1, \sim 1600$ minutes in the well CHN1-1B and $\sim 1800$ minutes in the well CHN2B. It can be thought that from the 120 minutes the pumping rate is relatively balanced with the groundwater flow from the aquifer its own and from the Red river upon a negligible influence of the river water level fluctuations on the groundwater level during this pumping time; after that $\sim 1000$ minutes of pumping, the groundwater level drawdown started to increase again until about the 2400th minute.

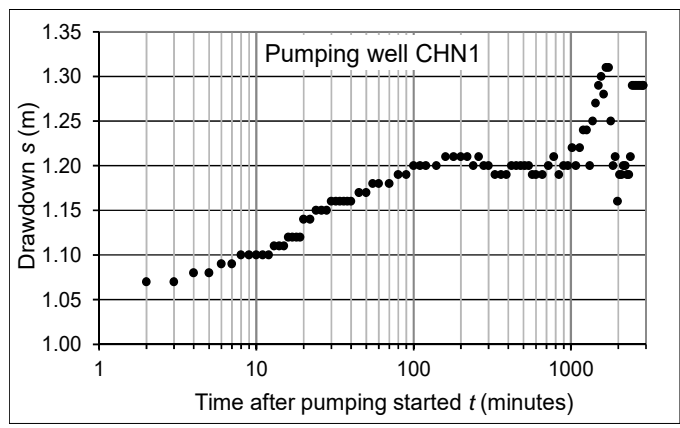

Figure 8. Time drawdown in pumping well CHN1

Therefore, utilization of water level drawdown data during the time between 120 minutes and 1600 minutes would give the most reliable value of parameter $L$.

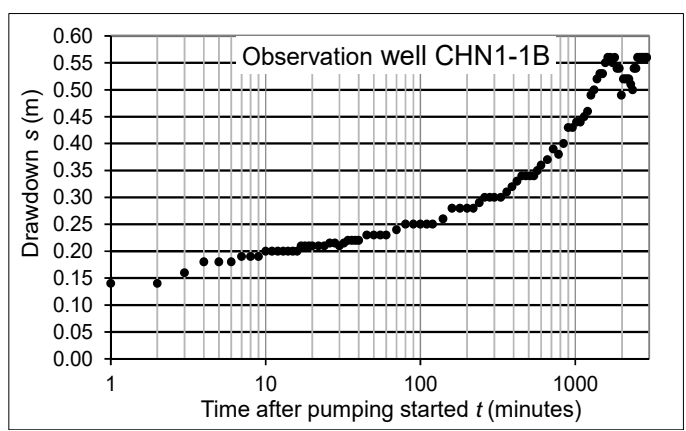

Figure 9. Time drawdown in observation well CHN1-1B

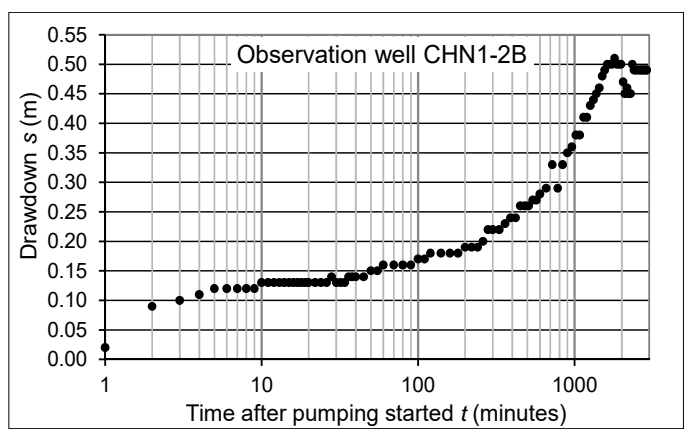

Figure 10. Time drawdown in observation well CHN1-2B

\section{Results}

\subsection{At time after pumping started $t=180$ minutes}

With $\Delta(\Delta h)=-0.059 \mathrm{~m}$ (Figure 7), substituting the measured drawdowns in well CHN1-1B and CHN1-2B into Eq. (4) and (5) results in the following:

$$
\left\{\begin{array}{l}
0.218=\frac{0.366 Q}{T} \lg \frac{(2 L-8.7)}{8.7} \\
0.121=\frac{0.366 Q}{T} \lg \frac{(2 L-21.1)}{21.1}
\end{array}\right.
$$

The solutions are $L=49.2 \mathrm{~m} ; \Delta L=25.6 \mathrm{~m} ; T$ $=1380.9 \mathrm{~m}^{2} /$ day; $A_{0}=0.475$ days.

\subsection{At time after pumping started $t=360$ minutes}

With $\Delta(\Delta h)=-0.118 \mathrm{~m}$ (Figure 7), substituting the measured drawdowns in well 
CHN1-1B and CHN1-2B into Eq. (4) and (5) results in the following:

$$
\left\{\begin{array}{l}
0.192=\frac{0.366 Q_{H}}{T} \lg \frac{(2 L-8.7)}{8.7} \\
0.112=\frac{0.366 Q_{H}}{T} \lg \frac{(2 L-21.1)}{21.1}
\end{array}\right.
$$

The solutions are $L=54.6 \mathrm{~m} ; \Delta L=30.0 \mathrm{~m} ; T$ $=1642.1 \mathrm{~m}^{2} /$ day; $A_{0}=0.503$ days.

For that two times of analysis, average values of the parameters are $T=1511.5$ $\mathrm{m}^{2} /$ day; $A_{0}=0.503$ days; $\Delta L=27.8 \mathrm{~m}$. 4.3 .

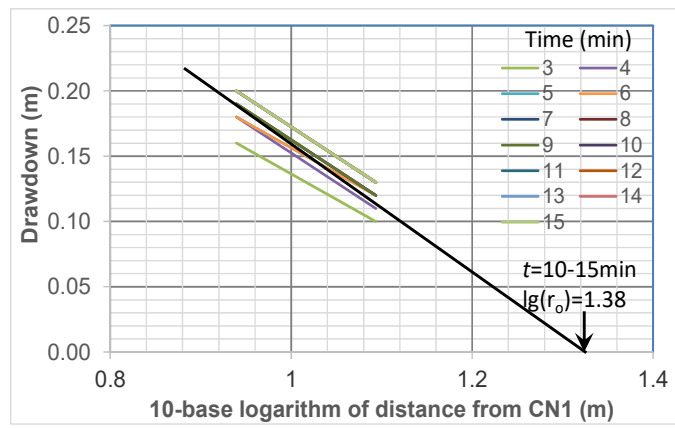

Figure 11. Distance drawdown (well CHN1-B and CHN1-2B) at pumping time: 15 minutes

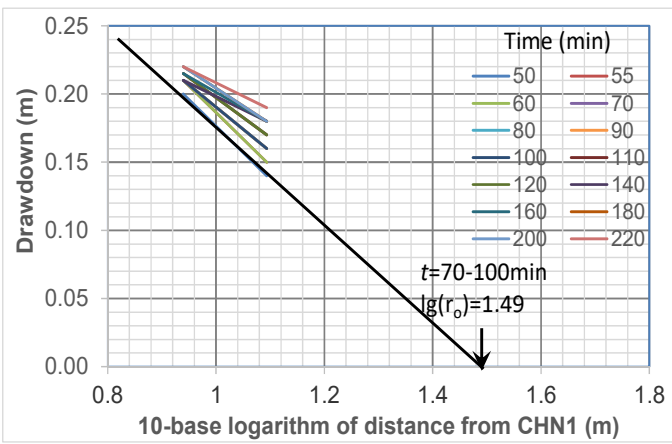

Figure 13. Distance drawdown (well CHN1-B and CHN1-2B) at pumping time: 50-220 minutes (an yearly time of 50 minutes is used)

\subsection{Inverse analysis procedure and final result}

The initially selected values of $T=1300$ $\mathrm{m}^{2} /$ day, $S^{*}=0.0001$ and $A_{0}=5$ days had resulted in $T=1511.5 \mathrm{~m}^{2} /$ day, $A_{0}=0.5115$
Determination of aquifer storage coefficient $S^{*}$

With average transmissivity of $T=1511.5$ $\mathrm{m}^{2} /$ day, it gave:

- $t=10-15$ minutes: $r_{\mathrm{o}}=24.0 \mathrm{~m}$ (Figure 11); $S^{*}=0.0042$;

- $t=36-40$ minutes: $r_{\mathrm{o}}=23.4 \mathrm{~m}$ (Figure 12); $S^{*}=0.00129$;

- $t=70-100$ minutes: $r_{\mathrm{o}}=30.9 \mathrm{~m}$ (Figure 13); $S^{*}=0.00167$;

Average aquifer storage coefficient is $S^{*}=0.00113$

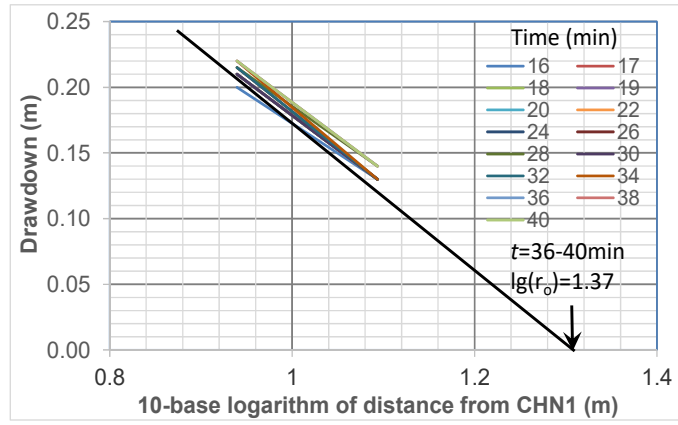

Figure 12. Distance drawdown (well CHN1-B and CHN12B) at pumping time: $16-40$ minutes

days. Using those obtained values to determine the groundwater level change $\Delta(\Delta h)$ caused by the Red river water level fluctuations and then determine new values of $T$ and $A_{0}$. This procedure repeats until an insignificant difference between the parameter values is achieved.

At time after pumping started $t=180$ minutes:

With $\Delta(\Delta h)=-0.057 \mathrm{~m}$ (Figure 14), substituting the measured drawdowns in well CHN1-1B and CHN1-2B into Eq. (4) and (5) results in the following:

$$
\left\{\begin{array}{l}
0.220=\frac{0.366 Q}{T} \lg \frac{(2 L-8.7)}{8.7} \\
0.123=\frac{0.366 Q}{T} \lg \frac{(2 L-21.1)}{21.1}
\end{array}\right.
$$

The solutions are $L=49.6 \mathrm{~m} ; \Delta L=25.0 \mathrm{~m} ; T$ $=1369.2 \mathrm{~m}^{2} /$ day and $A_{0}=0.457$ days. 
Trieu Duc Huy, et al./Vietnam Journal of Earth Sciences 40 (2018)

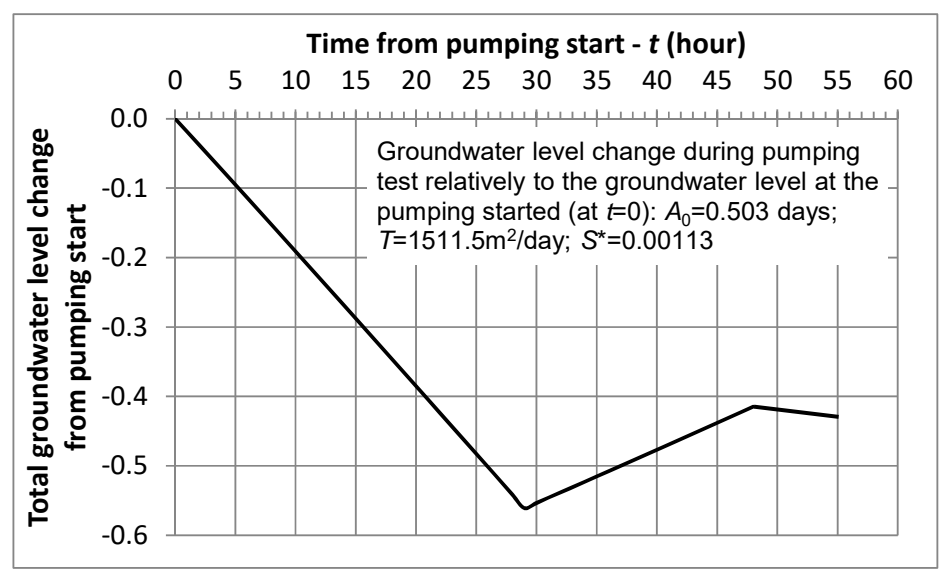

Figure 14. Total groundwater level change relatively to the groundwater level at the beginning of pumping at well

CHN1: $A_{0}=0.5115$ days, $T=1511.5 \mathrm{~m}^{2} /$ day, $S^{*}=0.00113$

At time after pumping started $t=360$ minutes:

With $\Delta(\Delta h)=-0.114 \mathrm{~m} \quad$ (Figure 14), substituting the measured drawdowns in well CHN1-1B and CHN1-2B into Eq. (4) and (5) results in the following:

$$
\left\{\begin{array}{l}
0.196=\frac{0.366 Q_{H}}{T} \lg \frac{(2 L-8.7)}{8.7} \\
0.116=\frac{0.366 Q_{H}}{T} \lg \frac{(2 L-21.1)}{21.1}
\end{array}\right.
$$

The solutions are $L=56.3 \mathrm{~m} ; \Delta L=31.7 \mathrm{~m} ; T$ $=1627.5 \mathrm{~m}^{2} /$ day; $A_{0}=0.617$ days.

For the that two analysis times, averages values of the parameters are $T=1498.4$ $\mathrm{m}^{2} /$ day; $A_{0}=0.537$ days; $\Delta L=28.4 \mathrm{~m}$

Table 1 summaries the results of the inverse analysis of just two steps of the trial and error of parameter determination. The results have shown that the values of the parameters converged very fast with the relative differences of $0.9 \%$ for transmissivity $T, 6.4 \%$ for $A_{0}$ and $2.1 \%$ for $\Delta L$.

Table 1. Summary of inverse analysis results

\begin{tabular}{|c|c|c|c|c|c|}
\hline Input of step 1 & Output of step 1 & $\begin{array}{l}\text { Relative difference } \\
\text { in step } 1(\%)\end{array}$ & Input of step 2 & Output of step 2 & $\begin{array}{c}\text { Relative difference } \\
\text { in step } 2(\%)\end{array}$ \\
\hline $\begin{array}{l}T=1300 \\
\mathrm{~m}^{2} / \text { day }\end{array}$ & $T=1511.5 \mathrm{~m}^{2} /$ day & $\mathrm{T}: 14.0 \%$ & $T=1511.5 \mathrm{~m}^{2} /$ day & $\begin{array}{l}T=1498.4 \\
\mathrm{~m}^{2} / \text { day }\end{array}$ & $T: 0.9 \%$ \\
\hline$S^{*}=0.0001$ & $S^{*}=0.00113$ & $A_{0}: 9.9 \%$ & $S^{*}=0.00113$ & $S^{*}=0.00113$ & $A_{0}: 6.4 \%$ \\
\hline$A_{0}=5.0$ days & $A_{0}=0.503$ days & $\Delta L: 65 \%$ & $A_{0}=0.503$ days & $A_{0}=0.537$ days & $\Delta L: 2.1 \%$ \\
\hline$\Delta L=80.6 \mathrm{~m}$ & $\Delta L=27.8 \mathrm{~m}$ & & $T=1511.5 \mathrm{~m}^{2} /$ day & $\begin{array}{l}\Delta L=28.4 \mathrm{~m} \\
K=55.5 \mathrm{~m} / \text { day }\end{array}$ & \\
\hline
\end{tabular}

\section{Discussion and Concluding remarks}

The the real values of aquifer parameters and riverbed layer's resistance are unique combination which scientifically and practically need to be determined. The estimated values of the parameters may be of very high errors if the boundary conditions and boundary conditions' values and one or some parameters' values are far from the real values. Tong Ngoc Thanh et al. (2017) and Nguyen The Chuyen (2017) have presented some arguments of wrong utilization of of a single Pleistocene confined aquifer without leakage from underlying Neogene aquifer in Thuong Tin district and Mo Lao-Ha Dong areas in determination of the Pleistocene aquifer transmissivity. Besides, the study of true hydrogeological aquifer structure is very important including the determination of the 
nature of the over-lying and lower-lying forformations in regards to the leakage to the main aquifer in the setting up the conceptual aquifer scheme, for which geophysical prospecting would be very helpful and effective (Nguyen Van Giang et al., 2014).

The determination of the exact boundary condition kinds, boundary values and aquifer parameters values for the areas along the Red river as well as for the areas of boundary of the Pleistocene aquifer with the bed rock in the West and South-West areas of the Red river plain have a very important role in the of the natural groundwater resources and groundwater abstraction potential along with the recharge components, which would also have a significant role in the soil hydrodynamic mechanics in the engineering geological problems, including land subsidence due to groundwater abstraction.

The analysis results have shown that the Pleistocene aquifer has relatively high hydraulic conductivity up to $55.5 \mathrm{~m} /$ day so the aquifer has very high capacity of water conduction and transmission water from the Red river to the abstraction facilities. The phenomenon of that the Pleistocene aquifer storage has a declining tendency with the pumping time is well corresponding with the physical nature that the compressibility of the aquifer little decreases with the aquifer pressure removal. This needs to be accounted in future actual groundwater modelling. A special feature is that the Red river bed layer has very insignificant resistance to the Pleistocene aquifer (0.537 days) which is corresponding to the increase of the distance of only $28.4 \mathrm{~m}$ to the river edge for utilization of the boundary as the first kind condition. Meanwhile the investigation during the 1990's years had shown that the leakage factor of about 130 days, which is corresponding to the increase of the river edge tin a distance of thousands of meters. This would be an argument to support the thought that the extensive sand and gravel excavation in the river has cause the removal of the fine bed materials of the river bed. This factor needs to be taken into consideration and into account in the design and assessment of groundwater abstraction of the abstraction facilities to be built along the Red river bank.

More studies and field experiments need to be carried out in the process of groundwater resources assessment and evaluation for the areas having surface streams which have a more or less interaction with groundwater aquifers, for which both the surface water and groundwater have significant role in water supply due to the spatial and temporal variations in order to have a real picture of the physical surface water and groundwater interaction through the est mates of leakage characteristics of the streambed to the aquifer, especially due to the nature of that the leakage parameter is a site specific.

From the present analysis results, it is worthwhile to come to the conclusion that the natural groundwater resources and the groundwater abstraction potential in Hanoi area in particular and other river plains in general need to be reassessed with the present streambed changes for the last few decades along with the hydrologic condition changes, including the climatic change.

\section{References}

Christensen S., 2000. On the estimation of stream flow depletion parameters by drawdown analysis. Ground Water, 38(5), 726-734.

Fetter C.W., 2001. Applied Hydrogeology. Prentice Hall-Upper Saddle River, NJ 07458.

Fletcher G. Driscoll., 1987. Groundwater and Wells. Published by Johnson Division, St. Paul, Minnesota 55112, USA.

Fox G.A., 2004. Evaluation of a stream aquifer analysis test using analytical solutions and field data. Journal of the American Water Resources Association. 40(3), 455-763. 
Trieu Duc Huy, et al./Vietnam Journal of Earth Sciences 40 (2018)

Hunt B., Wei J. and Clausen B., 2001. A stream depletion field experiment. Ground Water 39(2), 283-289.

John H. Cushman and Daniel M. Tartakovsky (Editors), 2017. The Handbook of Groundwater Engineering. Third Edition. CRC Press. Taylors \& Francis Group. 6000 Broken Sound Parkway NW, Suite 300.

Lough H.K. and Hunt B., 2006. Pumping test evaluation of stream depletion parameters. Ground Water. JulAug, 44(4), 540-546.

Mironhenco V.A. and Shestakov V.M., 1974. Fundamentals of hydromechanics. Publishers "Nedra", Moscow, Russia.

Ne-Zheng Sun, 1994. Inverse Problems in Groundwater Modeling. Cluwer Academic Publishers.

Nguyen Minh Lan, 2014. Report on "Study of the relationship between the Red river and groundwater, proposal of methods of determination of groundwater abstraction potential along the Red river from Son Tay to Hung Yen". Code: TNMT.02.33.

Nguyen Quoc Thanh and Nguyen Van Hoang, 2007. Hydrogeomechanical processes affecting the stability of Red river dike's foundation and in the Son Tay-Ha Noi area. Hanoi Geoengineering 2007. International Conference Proceedings, 120-123.

Nguyen The Chuyen, Vu Ngoc Duc, Dao Trong Tu, Nguyen Van Hoang, 2017. Study on determination of effective porosity and longitudinal dispersivity of aquifer and the application to field tracer injection test in Mo Lao, Ha Dong area, Hanoi, Vietnam. Vietnam National University Journal of Science, 33(1), 1-15.

Nguyen Van Giang, Nguyen Ba Duan, Le Ngoc Thanh, Noboru Hida, 2014. Hydro-geophysical Techniques to Aquifer Locating and Monitoring for Industrial zone north Thang Long and Quang Minh, Hanoi.
Vietnam J. Earth Sci., 36(3), 221-232. Doi: 10.15625/0866-7187/36/3/5905.

Nguyen Van Hoang, 2016. Modelling of water pollution. Vietnam Academy of Science and Technology Publishers.

Pham Dinh, 2016. Report on "Study of the effects of the sand and gravel excavation in the Red river and Thai Binh river system on the flow regime and bed load regime for supporting sustainable management and planning of sand and gravel excavation" code ĐTĐL.2012-T/27. Vietnam Academy of Water Resources.

Sophocleous M., 2001. Interactions between groundwater and surface water: the state of the science. Hydrogeology Journal, 10, 52-67.

Tong Ngoc Thanh, Trieu Duc Huy, Nguyen Van Kenh, Tong Thanh Tung, Pham Ba Quyen, Nguyen Van Hoang, 2017. Methodology of determining effective porosity and longitudinal dispersivity of aquifer and the application to field tracer injection test in Southern Hanoi, Vietnam. Vietnam J. Earth Sci., 39(1), 57-75. Doi: 10.15625/0866-7187/39/1/9228.

Tran Minh, 1984. Report on "Results of groundwater investigation in Hanoi area". Northern Union for Water Resources Planning and Investigation.

Trieu Duc Huy (Project head), 2015. Proposal "Groundwater protection in large cities (Hanoi city)" and the project's implementation data and materials. Vietnam National Center for Water Resources Planning and Investigation.

Vu Tat Uyen and Le Manh Hung, 2011. Warning on the consequences of sand and gravel excavation in the Red river more than the annual bed load supply. Journal of Water Resources Science and Technology, 3, 2-6. 